\title{
Mechanical Prestressing of Annealed Glass Beams Using Pretensioned GFRP: Characterisation and Potentiality
}

\author{
Mithila Achintha*, Bogdan Balan \\ School of Engineering, University of Southampton, Southampton, SO17 1BJ, UK \\ * Corresponding Author - E-mail: Mithila.Achintha@soton.ac.uk
}

\begin{abstract}
This paper presents the results of an experimental investigation on the mechanical behaviour of annealed glass beams prestressed using adhesively-bonded pretensioned Glass Fibre Reinforced Polymer (GFRP) strips. The results show that the glass beams prestressed using pretensioned GFRP showed an increased load capacity compared to equivalent glass beams reinforced with unprestressed GFRPs. The prestressed glass beams showed a notable ductile post-cracked behaviour similar to annealed glass beams reinforced with unprestressed GFRP strips. The results also show that the proposed glass prestressing technique prevented premature debonding of the GFRP strips from the glass beams and explosive final failure of the glass beams, unlike in the mechanically-prestressed glass beams investigated in the literature where these failures were commonly observed.
\end{abstract}

\section{Keywords:}

Annealed glass, Ductility, GFRP, Glass, Post-cracked, Prestress, Prestressed beams, Prestressing, Reinforcement, Residual stress 


\section{Introduction}

Owing to the distinctive combination of fascinating physical and chemical properties together with recent advances in glass technologies such as low emissivity, solar control, smart glass, etc., it is envisaged glass will play an increased and central role in future energy-efficient buildings. However, low tensile strength of glass (for example, compared to steel) and its brittle material behaviour pose challenges when glass is used as a load bearing material and/or in the form of large, complex geometries (e.g. facades, beams, columns, floors).

Only fully-toughened glass (also known as tempered glass) and heat-strengthened glass (i.e. partially-toughened glass), which are processed by expensive and energy consuming controlled thermal treatments of basic annealed glass (also known as float glass), are currently used in industry in load-bearing applications. Owing to differential cooling experienced during the thermal-treatment process, thermally-strengthened glass have compressive prestress (i.e. residual stress) in the surface regions. For instance, fully-toughened and heat-strengthened glass usually have surface compressive prestress of magnitude $80-150 \mathrm{MPa}$ and $24-52 \mathrm{MPa}$, respectively [1]. The initial surface compressive prestress means thermally-strengthened glass have higher apparent tensile strength in the surface regions compared to that of $20-40$ MPa of annealed glass. As glass fails due to the initiation/propagation of cracks in the surface regions, a surface compressive prestress ensures higher load resistance in thermallystrengthened glass compared to annealed glass. However, the balancing tensile residual stress in mid-thickness regions of thermally-strengthened glass, in particular in fullytoughened glass, causes a poor failure behaviour with no post-cracked load capacity.

Commercially available laminated glass which are produced by combining two or more glass sheets with one or more thin PolyVinylButyral (PVB) polymer or ionomer interlayers, usually display safe failure behaviour compared to monolithic glass [2]. Generally, combinations of tempered and annealed/heat-strengthened glass are used in laminated glass as a means of 
ensuring the required strength and the post-cracked ductility of glass structures. However, there are a few challenges when using laminated glass in building construction. Laminated glass are expensive compared to monolithic glass and all the processing steps must be carried out before lamination. It is difficult to arrange laminated glass in built-up structural geometries due to the difficulties associated with post processing and connecting laminated glass.

In addition to the use of laminated glass, use of annealed/heat-strengthened glass as built-up composite sections with a reinforcing material, such as steel (e.g. [3]), timber (e.g. [4]) or Fibre Reinforced Polymers (FRP) (e.g. [5], [6], [7], [8], [9]) has been investigated as an alternative means of ensuring strength and ductility in glass structures. Adhesively-bonded or mechanically-connected reinforcing material which is stronger than glass in tension has potential to carry the tensile stresses after glass has cracked. Similar to the polymer interlayer that holds broken glass in laminated glass structures, in cracked reinforced glass beams, the compressive stresses in unbroken glass pieces can keep the broken glass pieces locked in place whilst the reinforcement resists tension [7]. This behaviour ensures reinforced glass can resist a part of the original applied load even after the glass has cracked. Consequently, reinforced glass structures possess a notable displacement ductility. Experimental results reported in the literature suggest better ductility in reinforced annealed glass beams compared to that of reinforced tempered glass beams [3]. This is because rapidly progressing cracks cause complete fragmentation of tempered glass whereas annealed glass breaks into larger pieces.

The authors of this paper have previously [7] shown that in double-layer annealed glass beams reinforced with an adhesively-bonded thin Glass Fibre Reinforced Polymer (GFRP) strip, the combination of the GFRP and the top (i.e. compression) glass sheet ensured a notable load resistance in the beam after the bottom (i.e. tension) glass sheet has cracked. The reinforced beams showed a 'displacement ductility index', which was defined as the ratio of the additional midspan deflection after reaching the peak load (note: peak load is the load at which the 
bottom glass sheet fails in tension) to the midspan deflection at the peak load, greater than $400 \%$ [7]. However, as expected, despite the significant ductile behaviour of the reinforced glass beams, the GFRP reinforcement did not contribute to a notable increase in the load capacity of the beams. The bottom glass sheet of the reinforced double-layer glass beams still cracked when the tensile stress reached the tensile strength of the original annealed glass [7].

The present paper extends the previous work of the use of adhesively-bonded GFRP strips as reinforcement in double layer annealed glass beams [7] by introducing a pretensioned GFRP strip as a means of increasing the load capacity. The prestressed glass beams showed an increased load capacity compared to reinforced glass beams whilst ensuring a ductile postcracked behaviour similar that of the annealed glass beams reinforced with unprestressed GFRP strips.

\section{Mechanical Prestressing of Glass}

A surface compressive prestress has potential to improve the apparent tensile strength of glass. As stated in Section 1, although commercially available thermally-toughened glass possess a compressive prestress in the surface regions, toughened glass is not desirable from structural safety point of view since tempered glass fractures into small pieces [10-11]. Furthermore, tempered glass is expensive and it is impossible to make alterations (e.g. cutting, drilling). This makes the provision of complex geometries and connections that are required in modern glass structures is difficult. Commercially available chemically-toughened glass, which are not usually used in construction industry, poses additional challenges such as higher cost and effects due to less robust, thin surface compression layer [1].

Mechanical prestressing of glass beams and tension glass members using steel prestressing tendons/strips (e.g. [12-18]), a concept similar to prestressing (i.e. post-tensioning) of concrete beams [e.g. [19]], has been investigated in the literature as a means of improving apparent 
load capacity of glass structures. The use of mechanical prestressing has a number of advantages compared to the use of thermally-toughened glass. This provides the flexibility required to prestress glass after the glass structural elements had formed in to the required geometries within structures. A further advantage of mechanically prestressing is that by choosing the right force and the orientation of the prestressing tendons, a desirable prestress distribution that is tailored for the member under consideration can be provided, unlike in the case of commercially available toughened glass where the prestress level cannot be chosen at the construction sites. Another main advantage of mechanical prestressing is the ability of the prestressing tendons/strips to act as tension reinforcement after glass has cracked. This behaviour has potential to ensure a notable ductility in glass structures prior to the final failure. Nevertheless, due to high stored strain energy, ultimate failure of the mechanicallyprestressed glass beams studied in the literature were brittle and explosive compared to reinforced (i.e. with unprestressed reinforcement) glass beams [20].

Early examples of mechanical prestressing of glass structural elements include posttensioning of a glass ' $T$ ' beam using steel tendons placed at the bottom of the web of the cross section (i.e. tension side) [12]. As expected, cracks developed in the prestressed beam [12] at a relatively higher applied load compared to an equivalent reinforced (i.e. unprestressed) glass beam. Three approaches for mechanical prestressing of glass have been explored in the literature: mechanically-anchored prestressing tendons, adhesively-bonded prestressing tendons, and a combination of both mechanically-anchored and bonded prestressing tendons.

In mechanically-anchored prestressed glass systems reported in the literature, steel tendons usually in the forms of rods/bars/small hollow rectangular/square sections were integrated into laminated glass beams of 'I'/'H'/channel or box-shaped cross sections and mechanicallyanchored at the end of the beams (e.g. [12], [17]; [21], [22]). In these systems, the steel tendons were initially tensioned to a prescribed value using hydraulic jacks (e.g. [12]) or manually (e.g. [3]). Then, a compressive prestress was introduced into glass by transferring 
the force in the tendons into glass through specially designed end-connectors fixed at the end of the glass beams (e.g. [18]). Despite the simplicity of the concept, insufficient prestress transfer into the glass beams, premature failures caused by the misalignment between the end-connectors and the glass beams, and lateral buckling of glass beams during prestressing hamper the practical feasibility of the mechanically-anchored glass prestressing systems.

In glass beams posttensioned using adhesively-bonded prestressed tendons, the pretensioned steel tendons were bonded along an edge of the beam using an adhesive (e.g. [22], [23]). In these beams, it was required to hold the tension in the tendon using an external mechanism until the adhesive had fully cured. It is expected that after the adhesive has cured sufficiently, the bond between the glass and the prestressed tendon ensures transfer of a compressive stress into the glass beams. Adhesive connections usually ensure a composite action between different materials of the beam cross-section, and hence the flexural stiffness of a beam with adhesive-boned prestressed tendons is higher than an equivalent mechanically-anchored system. However, premature debonding of the tendons from the glass can hamper achieving the full potential of prestressing. Combined systems of mechanicallyanchored and adhesively-bonded pretensioned tendons have recently been investigated (e.g. [24]) as a means of delaying debonding of the tendons from the glass beams.

Research reported in the literature (e.g. [20], [22], [25], [26]) suggests the potential of mechanical prestressing of glass structures as a means of increasing the load capacity. In particular, the use of adhesively-bonded prestressing tendons appears to ensure higher efficiency in terms of increased load capacity and the flexural stiffness of the beams compared to those with mechanically-anchored pretensioned tendons. However, the use of steel tendons, mimicking the techniques used for prestressing concrete, means the existing adhesively-bonded mechanical prestressed systems unable to exploit the full potential of prestressing. Notably, the investigations into mechanical prestressing of annealed glass 
beams is very limited despite its practical benefits such as low cost, easy processing at construction sites, potential for post-cracked load resistance, etc. compared to thermallytoughened glass. There is a need for a method that is more practically feasible for prestressing glass, including annealed glass.

\section{Proposed Mechanical Prestressing Technique for Annealed Glass Beams}

The present study shows the use of adhesively-bonded thin pre-tensioned GFRP strips to prestress annealed glass beams. Relatively wide GFRP strips were used in the present study as a means to ensure a more uniform prestress across full width of the glass beam sections. It was also expected that, the use of a wide thin prestressed GFRP strip will reduce the development of high stress concentrations at the glass-GFRP bond areas. As shown by the results of the present paper (Sections 8 and 9), the prestressed glass beams tested in the present study experienced no premature GFRP bond failure or explosive final failure. The prestressed glass beams showed a higher load capacity compared to equivalent unprestressed annealed glass beams (see Section 8 and 9). GFRPs are translucent and hence glass with GFRP are translucent. The proposed GFRP prestressed annealed glass has applications in where translucent characteristics are useful (e.g. partition walls), and in applications where prestressing is required over a small area of glass, usually a highly stressed area where visual impact is not significantly affected due to the presence of GFRP strips (e.g. glass beams which support large glass panes/sheets).

\subsection{Materials}

Annealed glass, GFRP and an adhesive used in a previous study [7] of annealed glass beams reinforced with GFRP strips were used in the present study. Detailed characterisation of the mechanical properties of the materials can be found in elsewhere [7]; only the mechanical behaviour and the material properties relevant for the experimental work presented in the present paper are outlined below. 


\subsection{Glass}

$6 \mathrm{~mm}$ thick annealed glass, cut into dimensions $600 \mathrm{~mm} \times 40 \mathrm{~mm}$ by a commercial supplier, was used to make glass beams. No edge treatments were used on the glass sheets. The distributions and the sizes of the surface and the edge defects measured using an optical microscope were largely similar in all glass beam specimens [7]. Therefore, as a starting point, it was assumed that the experimental results of the overall load response and the failure behaviour of different beams may be compared with the assumption that the edge/surface defects were similar in all beams. Based on the results of four-point bending tests, the flexural tensile strength of glass was determined to be $39 \mathrm{MPa}$ [7]. The Young's modulus and the Poisson's ratio were assumed to $70 \mathrm{GPa}$ and 0.2 , respectively [2].

\subsection{GFRP}

GFRP strips were fabricated by impregnating a commercially available unidirectional 'E-glass' dry fibre sheets using a commercially available epoxy resin in a hand lay-up method [7]. The average thickness of the final cured GFRP laminate was $\sim 1.35 \mathrm{~mm}$. The strips were cut in to the same width as the glass beams (i.e. $40 \mathrm{~mm}$ ). The length of the GFRP strips was chosen to be $250 \mathrm{~mm}$ longer than that of the glass beams (i.e. $600 \mathrm{~mm}$ ) after taking into account the extra length that would require to fix the GFRP strips into a hydraulic loading machine for pretensioning. Using uniaxial tensile tests conducted in accordance with ASTM D3039-95a [27], the ultimate tensile strength, the Young's modulus and the Poisson ratio of the GFRP were determined to be $450 \mathrm{MPa}, 24.5 \mathrm{GPa}$ and 0.10 , respectively [7].

\subsection{Adhesive}

Bi-component epoxy adhesive "Araldite 2020" [28] was used in the present study to bond glass and GFRP. Based on an experimental investigation [7] on early strength gain of this adhesive, it was determined to cure the adhesive in an autoclave at $40^{\circ} \mathrm{C}$ for 24 hours, followed by further curing in ambient conditions for six days in order to achieve a glass-GFRP bond that was sufficient to transfer the prestress in the GFRP into the glass beams. The ultimate tensile 
strength and strain of the adhesive determined from uniaxial tensile tests that carried out in accordance with ASTM D638-02 [29] were $\sim 45 \mathrm{MPa}$ and $\sim 0.037$ respectively [7]. The results also suggested the tensile stress-strain relationship was largely linear at low strains (up to 0.0015). The initial Young's modulus and the Poisson's ratio of the adhesive were $3 \mathrm{GPa}$ and 0.45 respectively [7].

\section{Proposed Concept for Prestressing Annealed Glass Beams}

Fig. 1 shows a schematic representation of the methodology adapted for prestressing twolayer annealed glass beams. The GFRP strip was first tensioned using a hydraulic loading machine and the force in it was held using end-connectors fixed at both ends of the strip. Then, using the adhesive the GFRP strip was bonded onto glass sheets. The end-connectors were kept in place with the beam assembly (see Fig. 1) until the adhesive had cured sufficiently. As described previously (Section 3.4), it was expected that the adhesive bond would achieve a strength sufficient to transfer the force in the GFRP into glass beams after seven days of curing. Thus, the end-connectors were removed from the beam after seven days. It was anticipated that a compressive prestress was introduced into the glass beams through the harden glass-GFRP bond. Compared to the glass prestressing methods used in the literature such as mechanically-anchored tendons, no permanent anchorages were required in the present method. 


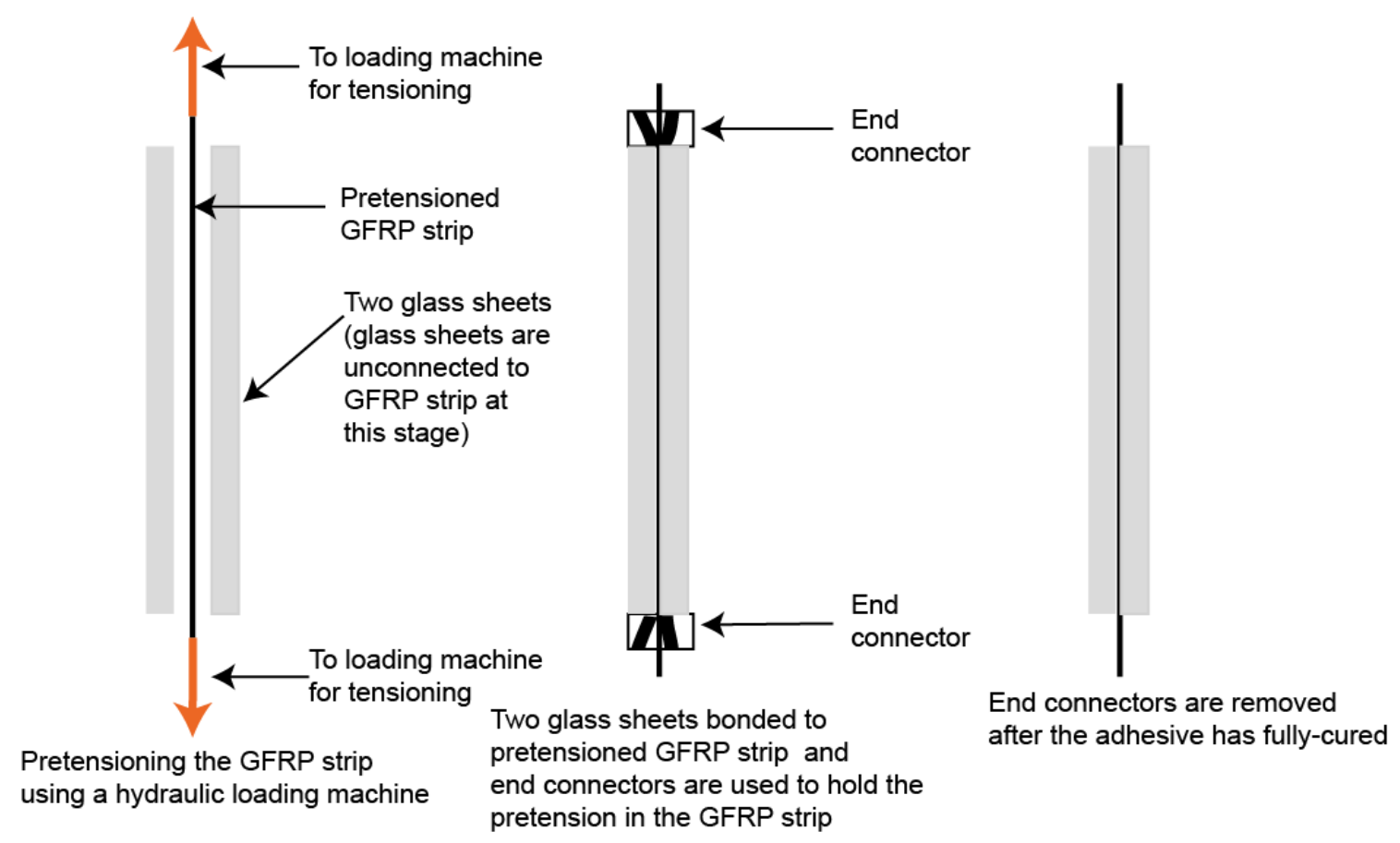

Fig. 1: Schematic representation of the proposed prestressing system for glass beams

Fig. 2 shows a prestressed glass beam after the end-connectors were removed from the beam. As shown in the figure, beams the were arranged for major axis bending given its convenience for practical applications due to the flexibility in using in a range of geometries, including areas around joints where a greater strength and a ductility are important. Furthermore, the high lateral stiffness of the beam ensured no bucking of the beam under prestress. The present arrangement of the prestressing also ensured a ductile failure with a notable post-cracked load resistance (see Section 8 and 9).

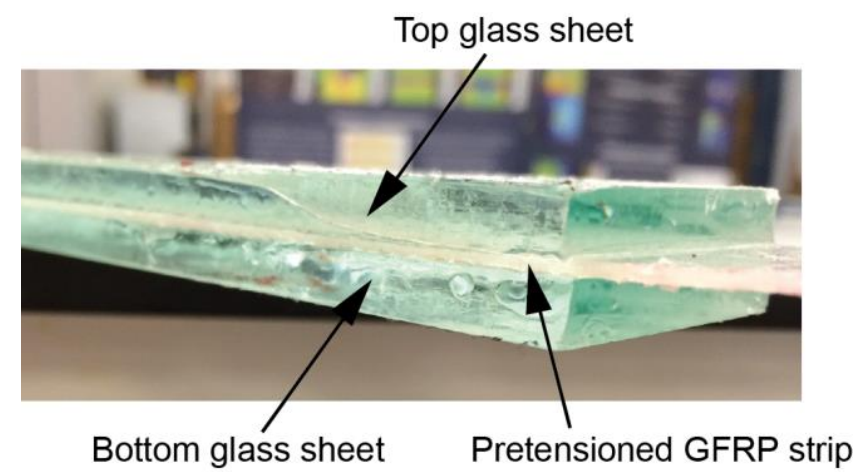

Fig. 2: Prestressed glass beam with an adhesively-bonded pretensioned GFRP strip 


\section{Pre-tension in the GFRP}

The design pretension in the GFRP strip depends on three major parameters: (i) tensile strength of the GFRP, (ii) the design prestress for the glass beam, and (iii) strength of the glass-GFRP adhesive bond. A preliminary experimental investigation of glass-GFRP shear tests suggested the strength of the glass-GFRP adhesive bond was indeed the critical parameter that would govern the design pretension in the GFRP strip. Therefore, it was determined to investigate the glass-GFRP bond firstly, and then to determine the design pretension for the GFRP strip using this knowledge. Checks against other two design parameters - i.e. tensile strength of the GFRP and the design prestress for the beam - were then carried out (Section 5.2).

\subsection{Glass-GFRP Adhesive Bond Test}

There is no widely accepted test geometry or a test standard for the determination of the glass-adhesive bond strength. A double-lap shear test specimen (Fig. 3) that was convenient to fabricate and test in a laboratory was used in the present study. $20 \mathrm{~mm}$ wide and $160 \mathrm{~mm}$ long GFRP strips were bonded between two $6 \mathrm{~mm}$ thick, $100 \mathrm{~mm} \times 75 \mathrm{~mm}$ pieces of annealed glass at each end of the glass assembly. As shown in Fig.3, each GFRP strip had a bond length of $30 \mathrm{~mm}$. The same GFRP material, adhesive and curing procedure used for the fabrication of prestressed glass beams were used in the bond experiments.

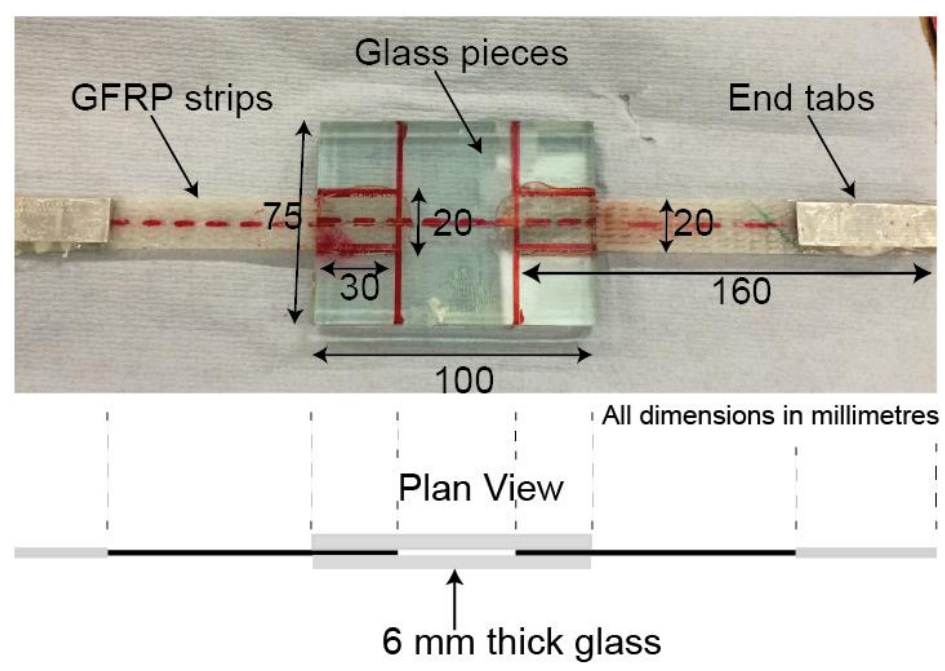

Fig. 3 : Bond test specimen 
The bond test specimen (Fig. 3) was loaded in tension using a servo hydraulic loading machine, displacement controlled at load rate $1 \mathrm{~mm} / \mathrm{min}$ (a load rate representative of a quasistatic load) until the failure. In order to ensure an adequate connection to the loading grips of the test machine, adhesively-bonded aluminium end tabs at the ends of the GFRP strips were used (see Fig. 3). For brevity, the results of one test specimen are discussed here; the results of a number of test specimens carried out in the present study were similar to the results presented here. It was also observed that the results of the bond tests were unaffected by the use of tin side or air side of the glass as the bond surface.

Fig. 4a shows typical failure observed in one of the bond-test specimens. The results suggest the glass-GFRP bond failed prior to the failure of the adherends. Fig. 4b shows the applied load-displacement relationship of one of the test specimens. The displacement data shown in Fig. 4b were the recorded data for the movement of the cross head of the test machine during testing. The displacement data was not critical or important in the present work, since the bond strength was determined using the knowledge of the maximum force resisted by the joint. The results suggest the maximum force resisted by the joint was $\sim 6.48 \mathrm{kN}$. 


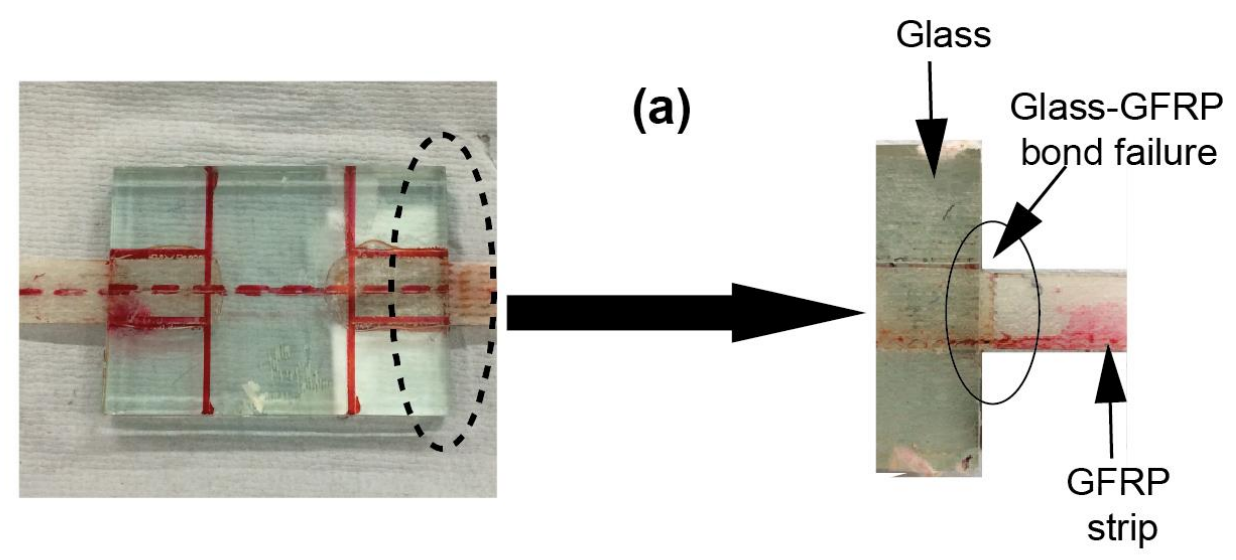

(b)

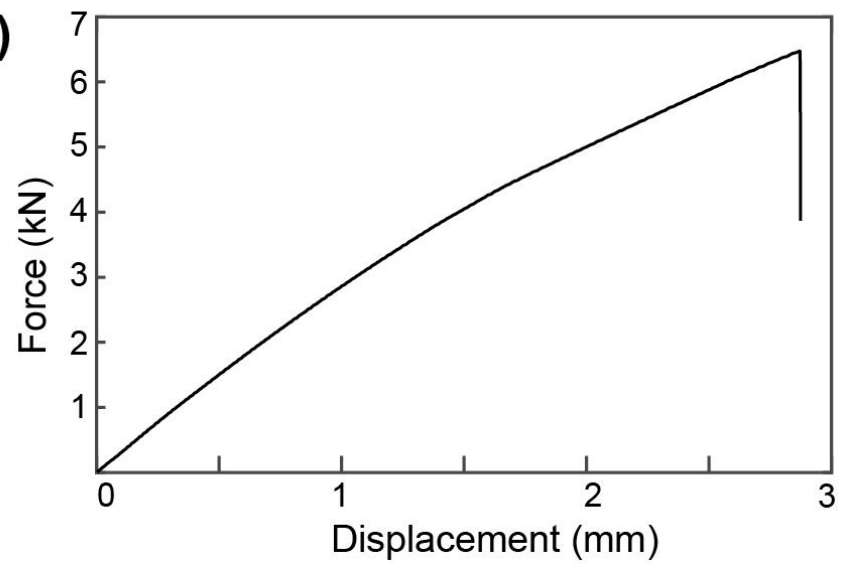

Fig. 4: (a) Glass-GFRP bond test: (a) Bond failure (b) Load-displacement relationship

\subsection{Design Pretension}

The knowledge of tensile stress in the GFRP strip at the recorded maximum load of the bond test was used to estimate a safe design pretension for the GFRP in the prestressed glass beams. The authors appreciate the fact that the localised high stress concentrations developed at critical locations in the adhesive joint may actually determine the bond strength, and hence an estimate of the strength of the glass-GFRP bond in the prestressed glass beams based on the knowledge of maximum load determined from a shear test may not be accurate. However, a detailed investigation of the failure of the glass-GFRP bond was beyond the scope of the present study, and given the complex nature of the problem means even a detailed study may still not provide a tool to accurately predict the glass-GFRP bond strength in the prestressed glass beams. In order take into account the uncertainties associated with the estimate of the design pretension that was determined based on the results of the bond test, an arbitrary safety factor of three was used in the present study as a means of ensuring a safe design pretension in the GFRP strip. 
Using the knowledge of the peak load resistance of the bond test (i.e. $6.48 \mathrm{kN}$ ), the average tensile stress in the GFRP at the peak load was determined to be $240 \mathrm{MPa}\left(=\frac{6.48 \times 1000}{20 \times 1.35}\right.$ $\mathrm{N} / \mathrm{mm}^{2}$ ). This peak tensile stress (240 MPa) is lower than the yield strength of the GFRP (450 MPa) (Section 3.3). This ensured no GFRP failure during pretensioning of the GFRP strip. By combing the knowledge of maximum average tensile stress in the GFRP (i.e. $240 \mathrm{MPa}$ ) with the arbitrary assumed safety factor of three, a safe design prestress in the GFRP was determined to be $80 \mathrm{MPa}$. Thus, the design pretension force for the GFRP strip in the glass beams was determined to be $4.22 \mathrm{kN}\left(=\frac{80 \times 40 \times 1.35}{1000} \mathrm{kN}\right.$, where $40 \mathrm{~mm}$ and $1.35 \mathrm{~mm}$ are the width and the thickness of the GFRP strip; see Section 3.3). Assuming a full and uniform transfer of the pretension in the GFRP strip into the glass beams, the expected average compressive prestress in the glass beam was determined to be $8.8 \mathrm{MPa}\left(=\frac{4.22 \times 1000}{2 \times 40 \times 6} \mathrm{~N} / \mathrm{mm}^{2}\right.$, where $40 \mathrm{~mm}$ and $6 \mathrm{~mm}$ are the width and the thickness of a glass sheet; see Section 3.2). Compressive prestresses of similar and higher magnitudes were achieved in prestressed glass beams studied in the literature (e.g. [12]), and therefore it was assumed that no premature buckling or material failure of the glass beams would happen under this prestress.

\subsection{Pre-tensioning the GFRP strip}

The GFRP strip was pretensioned using a hydraulic loading machine. Two end-connectors, each made from two $10 \mathrm{~mm}$ thick steel plates (see Fig. 5a) were connected at each end of the pretensioned GFRP strip whilst it was still in the loading machine. Each end-connector was tightened using four $10 \mathrm{~mm}$ friction grip bolts (40 Nm torque) in order to hold the GFRP strip inside the connector (Fig. 5a). The friction forces exerted by the inner surfaces of the steel plates on the GFRP strip were able to retain the pretension after the GFRP strip was removed from the loading machine. However, a loss in pretension was expected, since a slip of the GFRP strip was inevitable due to the inefficiency of the end-connectors. Since the objective of the study was not to design efficient end-connectors, but to use a simple system that can 
hold a pretension which would be sufficient to introduce the design prestress in the glass beams, the end-connectors shown in Fig. 5 a were used in the present study.

Since a loss in pretension was expected, it was decided to pretension the GFRP strip to a load higher than the design value of $4.22 \mathrm{kN}$ (Section 5.2). This actual pretension required for the GFRP strip was determined from an experimental study involving separate GFRP strips prestressed to several prescribed initial forces and then investigating the pretension remained after the removal of the GFRP strip from the loading machine. Strain gauges fixed at the middle region of these GFRP strips were used to estimate the stress during and after the pretensioning. To simulate the case of a real prestressed glass beam test specimens, two glass sheets were also placed between the pretensioned GFRP prior to fixing the endconnectors. However, the glass sheets were not bonded to the GFRP strip. Thick ( $3 \mathrm{~mm})$ rubber were used (see Fig. 5a) to prevent direct contact of glass and steel. The prestressing process of the actual glass beams test specimens is discussed in Section 6.

Fig. 5b shows the variation of the tensile stress in GFRP strip with time when it was tensioned up to $\sim 11.8 \mathrm{KN}$ (i.e. maximum average tensile stress $\approx 220 \mathrm{MPa}\left(=\frac{11.8 \times 1000}{40 \times 1.35} \mathrm{~N} / \mathrm{mm}^{2}\right)$ and then removed from the loading machine after the end-connectors were fixed. The GFRP stresses shown in Fig. 5b were calculated by combining the knowledge of the measured strain data and the Young's modulus of the material (24.5 GPa, Section 3.3). The stress data shown in Fig. 5b suggest that the stress in the GFRP was dropped to 100-80 MPa after it was removed from the loading machine. It was decided that this level of pretension in GFRP would be appropriate given the target design pretension in the GFRP was $80 \mathrm{MPa}$ (Section 5.2). 


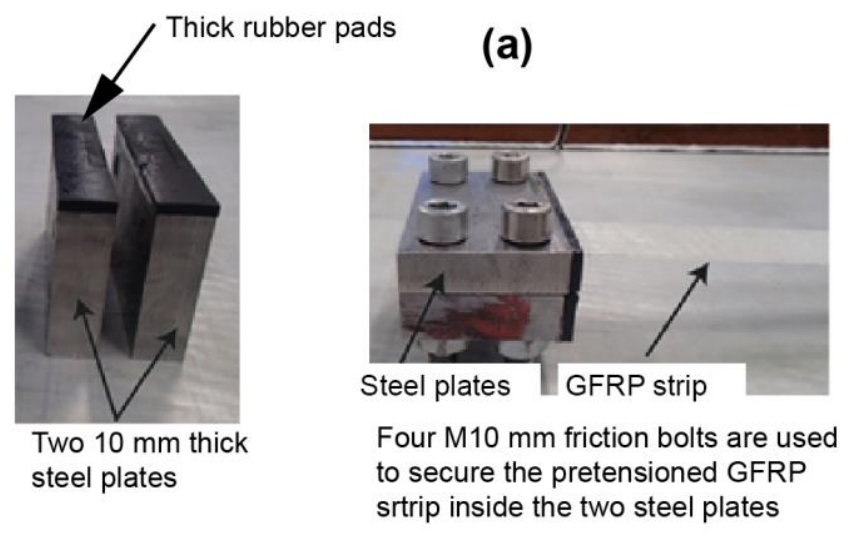

(b)

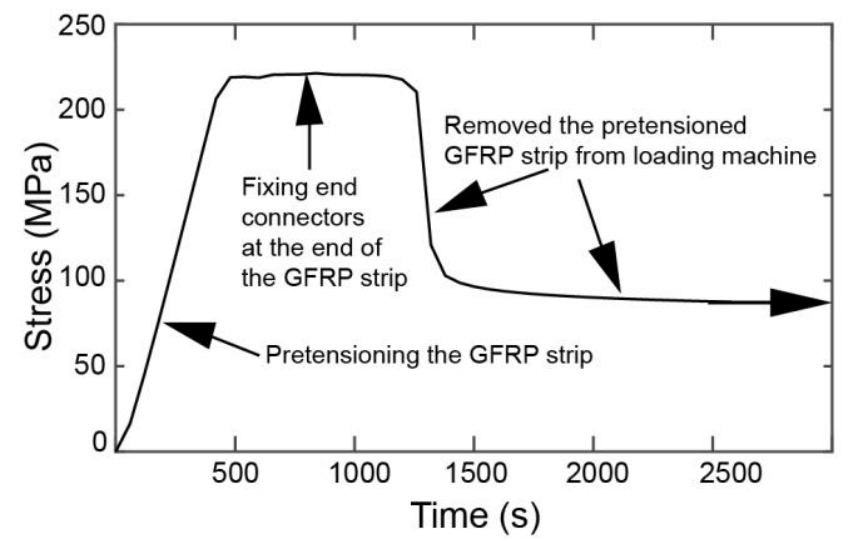

Fig. 5: (a) End-connector (b) Variation in the tensile stress in GFRP with time

\section{Prestressing of Glass Beams}

The GFRP strip was first tensioned up to a force of $\sim 11.8 \mathrm{kN}$ using a hydraulic loading machine (see Fig. 6a) at a displacement rate of $1 \mathrm{~mm} / \mathrm{min}$ representing a static load scenario. Whilst the maximum applied tensile force was acting on the GFRP strip two glass beam specimens (size $600 \mathrm{~mm} \times 40 \mathrm{~mm} \times 6 \mathrm{~mm}$, Section 3.2) were bonded to each side of the GFRP using Araldite 2020. Prior to bonding, all bond surfaces of the GFRP strip and the glass sheets were thoroughly cleaned and degreased using acetone. The volume of the adhesive required to obtain a thin layer of $\sim 0.1 \mathrm{~mm}$ was evenly spread using a spatula over the bond surfaces of each glass beam specimen. The viscosity of the adhesive was sufficient to apply the adhesive on the surfaces of the vertically orientated glass surfaces. Glass beam specimens were then carefully bonded to the GFRP strip whilst ensuing no air bubbles were trapped in between. As shown in Fig. 6b, the glass beam was then secured using a duct tape to prevent potential 
leaks, if any, of the adhesive. The end-connectors were then fixed to the beam (See Fig. 6b). The beam was then removed from the loading machine and cured for seven days as described in Section 3.4 (i.e. 24-hour autoclave curing at $40^{\circ} \mathrm{C}$ temperature and atmospheric pressure, followed by further curing under ambient conditions for six more days).

(a)

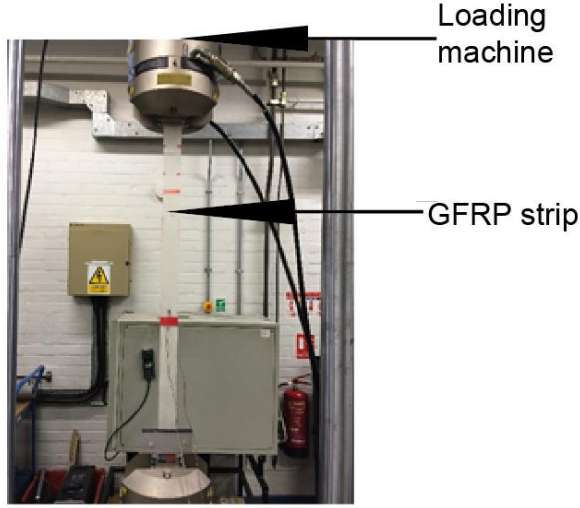

Pretensioning the GFRP strip

(b)

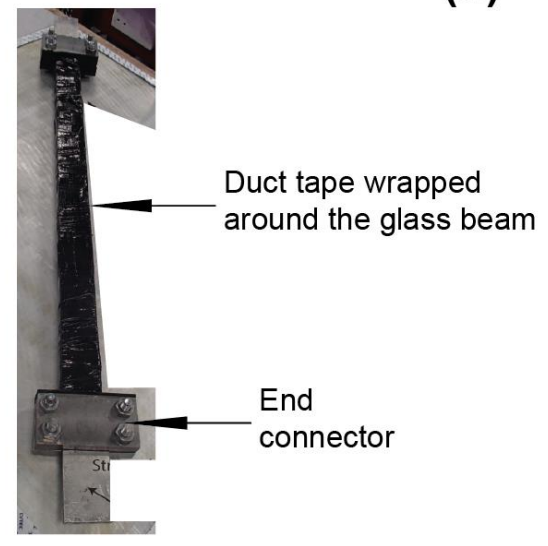

Two glass sheets those will be bonded to the GFRP strip

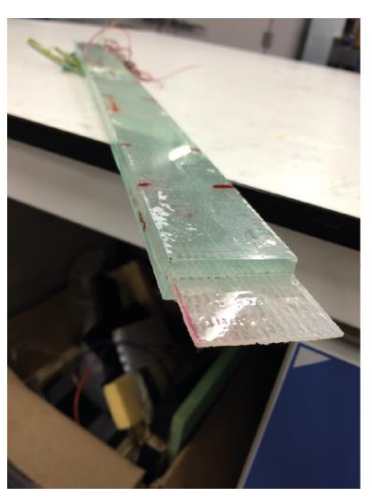

End connectors fixed at the ends of the glass beam

Prestressed glass beams after the removal of the end connectors

Fig. 6: (a) Pretensioning the GFRP strip and bonding two glass beam specimens. (b) Glass beam before and after the removal of the end-connectors.

\section{Experimental Determination of the Prestress in Glass Beams}

A scattered light polariscope, SCALP-05 [10, 30], was used to measure the prestress introduced into the glass beams. SCALP-05 uses glass birefringence that changes the polarisation of an input laser beam and the consequent variation in the optical retardation of 
the scattered light to determine the stress at a given location of glass. Details of the use of SCALP-05 to measure stresses in glass can be found in elsewhere [10,30].

In the present study, stress components in both longitudinal $\left(\sigma_{x}\right)$ and transverse $\left(\sigma_{y}\right)$ directions of the prestressed glass beams were measured after the end-connectors were removed (i.e. after seven days of curing of the beams). Polaricopes usually accurately measure the stresses within the surface regions of glass, but the measurement of stress data at mid-thickness regions of thick glass are less reliable [10]. The polariscope used in the present study (SCALP05) [30] usually provide accurate stress measurements in glass up to $\sim 3 \mathrm{~mm}$ from the surface [10]. Therefore, in the present study, stresses were measured up to $\sim 3 \mathrm{~mm}$ deep from both top and bottom sides of the two-layer glass beams.

Fig. 7a shows the measured $\sigma_{x}$ stress data at midspan of one of the prestressed glass beams. For brevity, the measured stress data of one beam specimen are presented in this paper. The presented results are representative of all (more than three) test beams investigated in the present study. The results (i.e. broken lines in Fig. 7a) show that the compressive stress at the each surface of the prestressed glass beam was $\sim 13 \mathrm{MPa}$, and the magnitude of the compressive stresses decreased towards mid-thickness region. However, since glass has some initial prestress (i.e. residual stress) owing to its manufacturing process $[10,11]$, these measured stresses may not be the actual prestress caused by the pretensioned GFRP strip.

It was decided to determine the actual prestress caused by the pretensioned GFRP By subtracting the residual stress from the measured stress data. The residual stress in the original glass beams (shown by dotted lines in Fig. 7a) was determined by measuring the stress in the surface regions of a reference beam - i.e. a similar two-layer glass beam reinforced with an unprestressed GFRP strip. The results shows the surface compressive residual stress of the reference beam was $\sim 7 \mathrm{MPa}$. The solid lines in Fig. 7a shows the 
prestress caused by the prestensioned GFRP strip which was obtained by subtracting the stress in the reference beam from that in the prestressed beam. The results suggest the prestress at the surfaces of the glass beam was 6-7 MPa. This value comparable with the expected design prestress of 8.8 MPa (Section 5.2).

In order to further justify the value of the prestress determined above, it was decided to investigate the stress data in the transverse direction (i.e $\sigma_{y}$ stress) of the two beams. Fig. $7 \mathrm{~b}$ shows the measured $\sigma_{y}$ stress. As expected, the measured $\sigma_{y}$ stress for the two beams were almost similar. This suggests the prestress determined above (shown by solid lines in Fig. 7a) was indeed the actual prestress caused by the pretension in the GFRP strip, since the pretension in the GFRP could not introduce a notable prestress in the transverse direction.

(a)

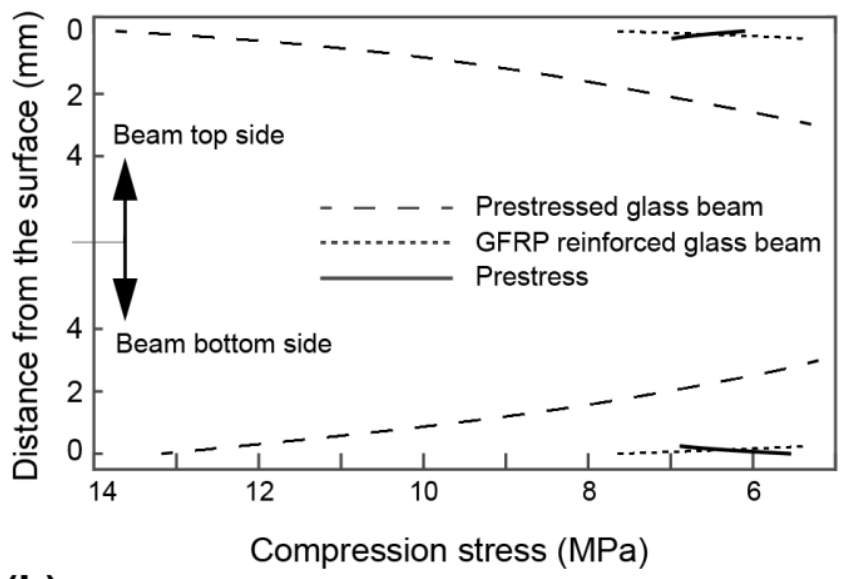

(b)

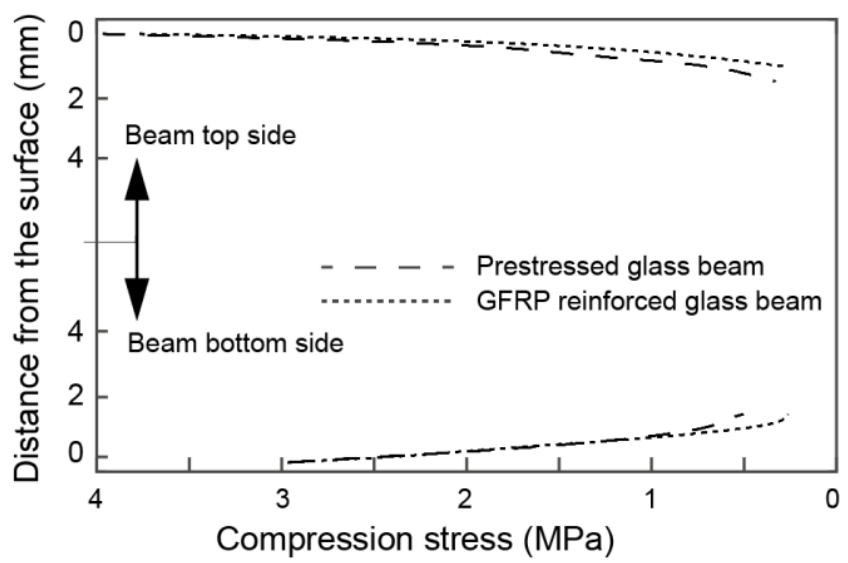

Fig. 7: Stress in the surface region of the prestressed and the reference glass beams: (a) $\sigma_{x}$ (b) $\sigma_{y}$ 


\subsection{Uniform Distribution of Prestress along the Beam Span}

The results in Fig. 7a (solid lines) show the prestress caused by the pretension in the GFRP strip at midspan of the prestressed glass beam. The uniformity of this prestress along the beam span was investigated by measuring the longitudinal stress $\left(\sigma_{\mathrm{x}}\right)$ at a number of arbitrary chosen span locations of the beams (Fig. 8a shows the chosen locations). Fig. 8b shows the measured $\sigma_{x}$ data at $100 \mathrm{~mm}$ from each end of the glass beam (locations $L_{1}$ and $L_{4}$ ), at beam midspan $\left(L_{2}\right)$, and at $200 \mathrm{~mm}$ from the right hand end $\left(L_{3}\right)$ of one of the prestressed glass beams. The results show the measured $\sigma_{x}$ stresses were similar. Similarly, as expected, the measured $\sigma_{x}$ stress data (not shown in the present paper) at similar locations of the reference beam (i.e. residual stress in the original glass beams) were similar to that shown by dotted lines in Fig. 7a. The results suggest that the pretension in the GFRP strip introduced a largely uniform prestress distribution along the span of the prestressed glass beam.

(a)

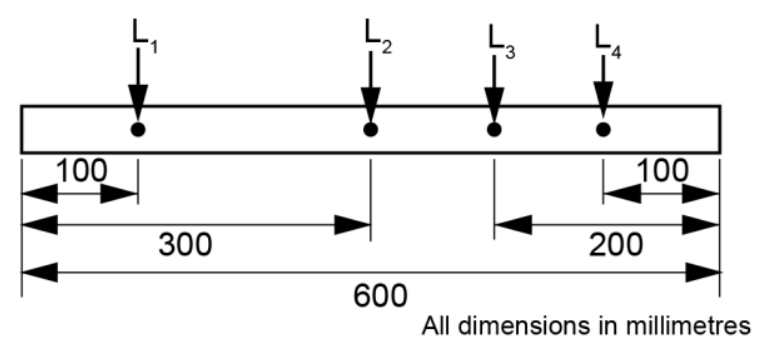

(b)

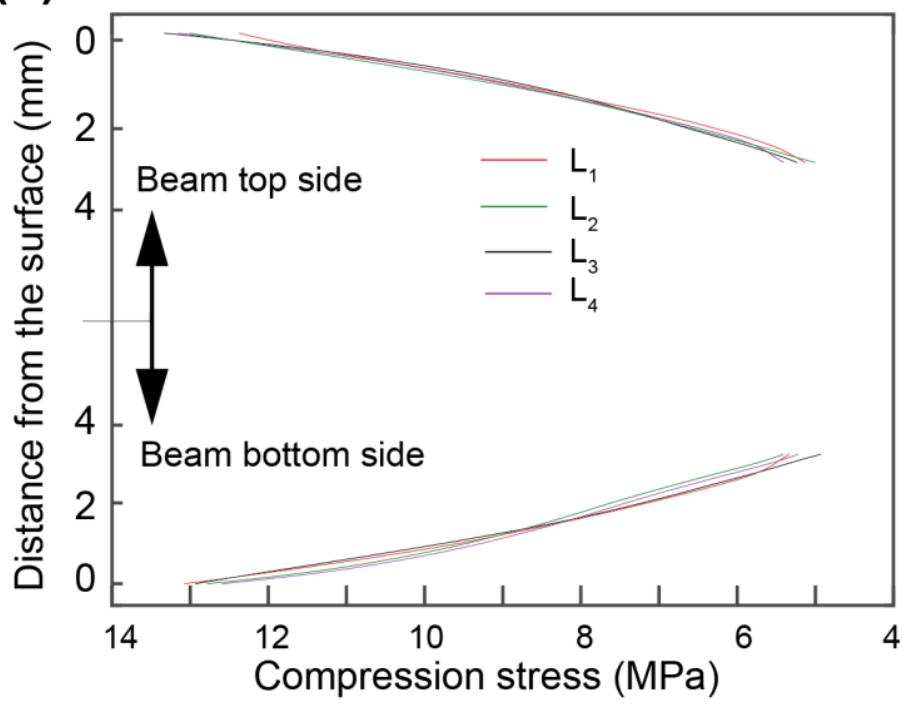

Fig. 8: $\sigma_{x}$ stress in the surface region along the beam span: (a) Stress measurement locations (b) Measured $\sigma_{x}$ stress data 


\section{Beam Tests and Results}

The load response and the failure behaviour of the prestressed glass beams were experimentally investigated seven days after the fabrication. The end-connectors were removed from the beams prior to the testing of the beams. The results of the prestressed beams were compared against two types of reference glass beams: (1) adhesively-bonded double-layer glass beams (i.e. with no GFRP reinforcement) and (2) double-layer glass beams reinforced with an adhesively-bonded unprestressed GFRP strip. All the beams were made using the materials described in Section 3. The prestressed glass beams were fabricated and prestressed as described in Section 6. The reference beams were also fabricated in a similar way, but without a GFRP strip (i.e. adhesively-bonded double-layer glass beams) and with an unprestressed GFRP strip (i.e. double-layer glass beams reinforced with an adhesivelybonded unprestressed GFRP strip), respectively. The fabrication details of the reference beams can be found in elsewhere [7].

All the glass beams were $600 \mathrm{~mm}$ long and tested in four-point bending with a constant moment zone of $400 \mathrm{~mm}$ and two equal shear spans of $50 \mathrm{~mm}$ (Fig. 9) at displacement controlled at rate $1 \mathrm{~mm} / \mathrm{min}$, a slow rate representative of a static load. The vertical deflection at midspan of the beams were measured using digital displacement gauges. Strain data of the beams were recorded using strain gauges attached on the top (i.e. tension) and the bottom (i.e. compression) surfaces of the double-layer glass beams at midspan. Surface tension and compression stresses at midspan of the beams were also recorded using SCALP-05.

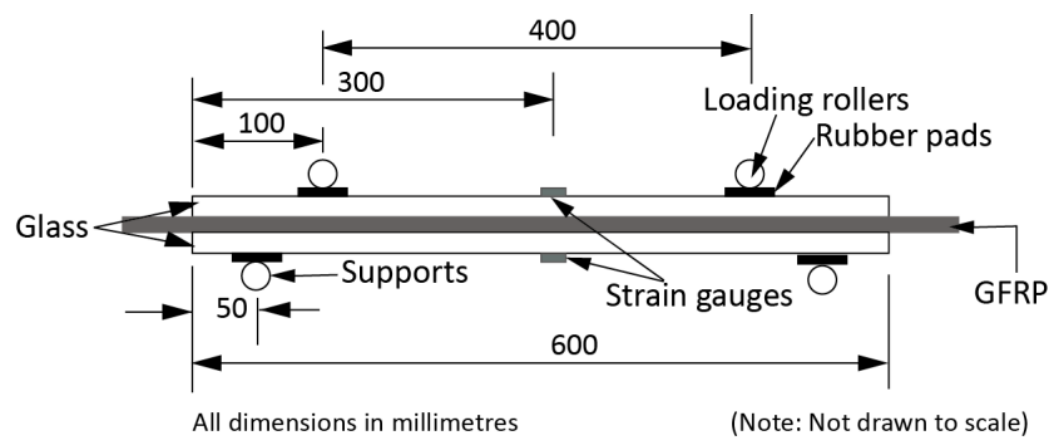

Fig. 9: Four-point bending test arrangement of the glass beams 


\subsection{Pre-cracked Regime}

\subsubsection{Load-displacement relationships}

Fig. 10a shows the applied load vs. midspan deflection relationships of three prestressed glass beams. For brevity, only the results of three beams are presented in Fig. 10a; these results are representative of all the prestressed glass beams tested in the present study. As can be noted from the figure, the beams showed largely linear load-midspan deflection relationships during the initial regime of the loading (i.e. prior to attaining the peak load) where the glass beams remained uncracked. The recorded peak load of the three test beams were $2140 \mathrm{~N}$, $2160 \mathrm{~N}$ and $2230 \mathrm{~N}$, respectively. The recorded midspan deflection of the three beams at the respective peak loads were $3.74,3.82$ and $3.84 \mathrm{~mm}$. The observed results of the three beams agreed with each other; the marginal differences were expected given the potential variations in the prestress in the beams and the actual tensile strength of each glass beam. A detailed investigation of these inevitable small differences was beyond the scope of the present paper, since the objective was not to provide design data based on a large pool of experiments, but to demonstrate the potential benefits of the proposed adhesively-bonded GFRP prestressing technique for annealed glass beams.

\subsubsection{Stress evolution}

By combining the knowledge of the Young's modulus of glass, which was assumed to be 70 GPa [2]) and the recorded strain gauge data, the surface stresses at the beam midspan were determined. Fig. 10b shows the midspan stress data of one the prestressed glass beams. The results of the other beams were similar to that presented in Fig. 10b. The figure shows the stress data prior to the tensile failure of the bottom glass sheet (i.e. prior to the attainment of the maximum load resistance), since no strain data were reliably recorded after the bottom beam has cracked. The surface stresses at beam midspan zone were also measured using SCALP-05 at two arbitrary chosen applied load values (510 N and $1100 \mathrm{~N}$, respectively). The 
results shown in Fig. 10b suggest the stresses calculated from the strain gauge data agree with those measured using SCALP-05.
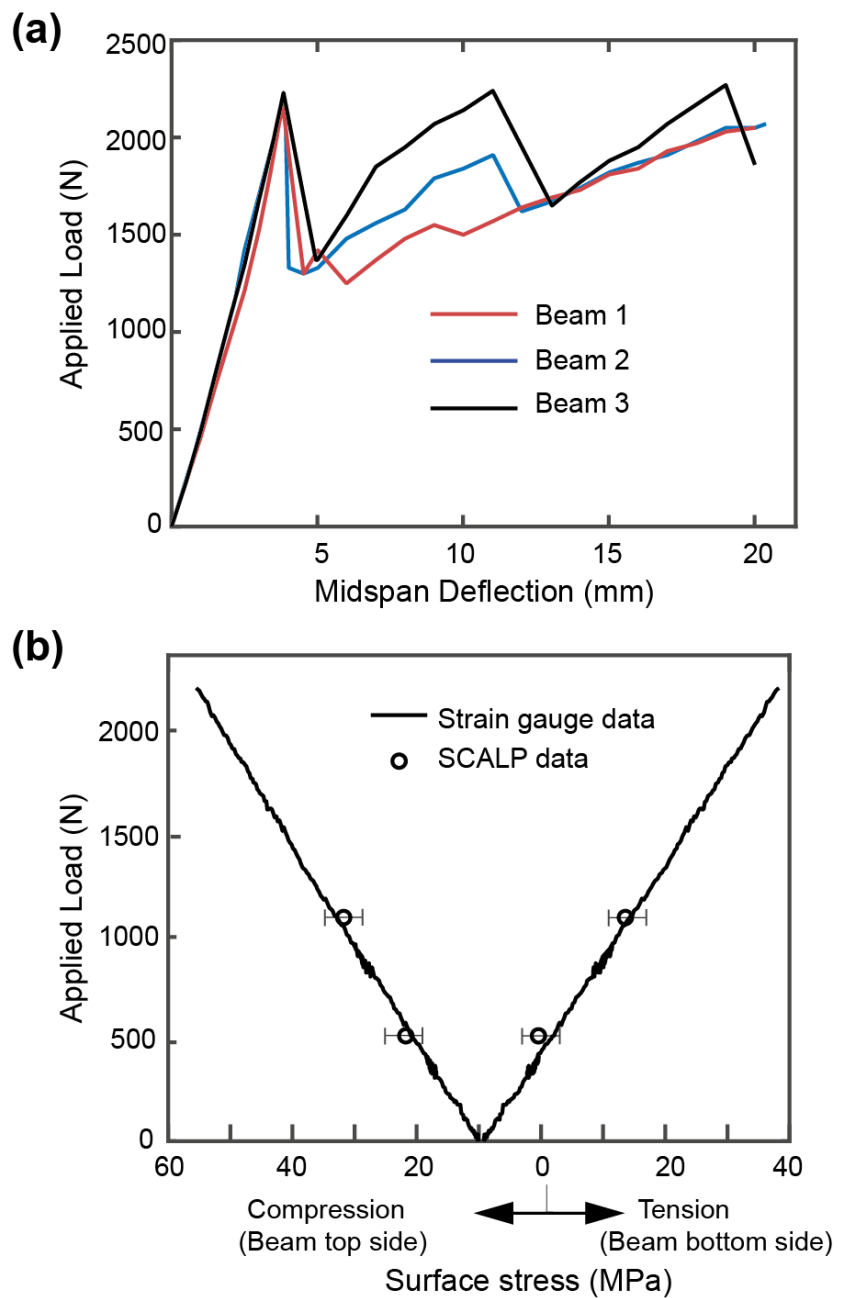

Fig. 10: Experimental results of the prestressed glass beams: (a) Load-midspan deflection relationships. (b) Measured surface stress data at midspan

The results (Fig. 10b) show the surface stresses increased linearly with the increase of the applied load. The surface stresses at the maximum load of the beam were $\sim 38 \mathrm{MPa}$ (tension) and $\sim 54 \mathrm{MPa}$ (compression), respectively. Using the results of the experiments of similar fourpoint bending tests, the strength of annealed glass was determined to be $\sim 38-40 \mathrm{MPa}$ in tension and $\sim 47 \mathrm{MPa}$ in compression [7]. Thus, the results suggest the bottom (i.e. tension) surface of the prestressed beam failed when the actual tensile stress (i.e. actual tensile stress $=$ applied tensile stress - magnitude of the surface compressive prestress) reached the 
flexural tensile strength of annealed glass. However, the increase of $\sim 7 \mathrm{MPa}$ in the maximum surface compression compared to reference beam (i.e. $54 \mathrm{MPa}$ (prestressed beam) compared to $47 \mathrm{MPa}$ (original annealed glass)) suggests an effect of a compressive prestress of magnitude $\sim 7 \mathrm{MPa}$ in the prestressed glass beams. This prestress of $\sim 7 \mathrm{MPa}$ comparable with the average prestress of $\sim 6-8 \mathrm{MPa}$ measured in the prestressed glass beams prior to testing (Section 7).

\subsection{Post-cracked Behaviour of Prestressed Glass Beams}

As depicted by Fig. 10a, a sudden drop in the load resistance of the prestressed glass beams were occurred after the attainment of the respective peak load. This drop was due to the formation of a major crack in the bottom (i.e. tension) glass sheet. The development of cracks in the bottom glass layer caused a reduction in the flexural stiffness of the beams, consequently resulted in increase in deflection. For example, the midspan deflection of the beams increased by $20 \%$ (from 3.74 to $4.50 \mathrm{~mm}$ ), 19\% (from 3.82 to $4.53 \mathrm{~mm}$ ) and $29 \%$ (from 3.84 to $4.95 \mathrm{~mm}$ ), respectively soon after the peak load. However, since the beams were tested displacement controlled, the combination of the GFRP and the top glass sheet continued to carry some load in the post-cracked regime. The behaviours of all three beams in the post-cracked regime were similar (Fig. 10a). Whilst the load-resistance of the beams continued to increase with the increase of the applied displacement, further cracks were developed in glass.

Fig. 11 shows the final crack pattern observed in the beams (for brevity, only the results of one beam is presented in Fig. 11). Observations of the cracked beam suggested that the GFRP held the cracked glass pieces together despite continuous cracking developed in the beam during the post-cracked regime. This behaviour contributed to maintain a notable bending stiffness in the cracked beam. The load resistance of all cracked beams increased markedly beyond the initial load resistance at the beginning of the post-cracked regime (Fig. 10a). The tests were stopped when the midspan deflection of the beams reached $\sim 20 \mathrm{~mm}$. 
The load resistance of the beams at this maximum displacement were 2070, 2050 and 1860 $\mathrm{N}$, respectively; $97 \%, 95 \%$, and $83 \%$ of the respective peak load.

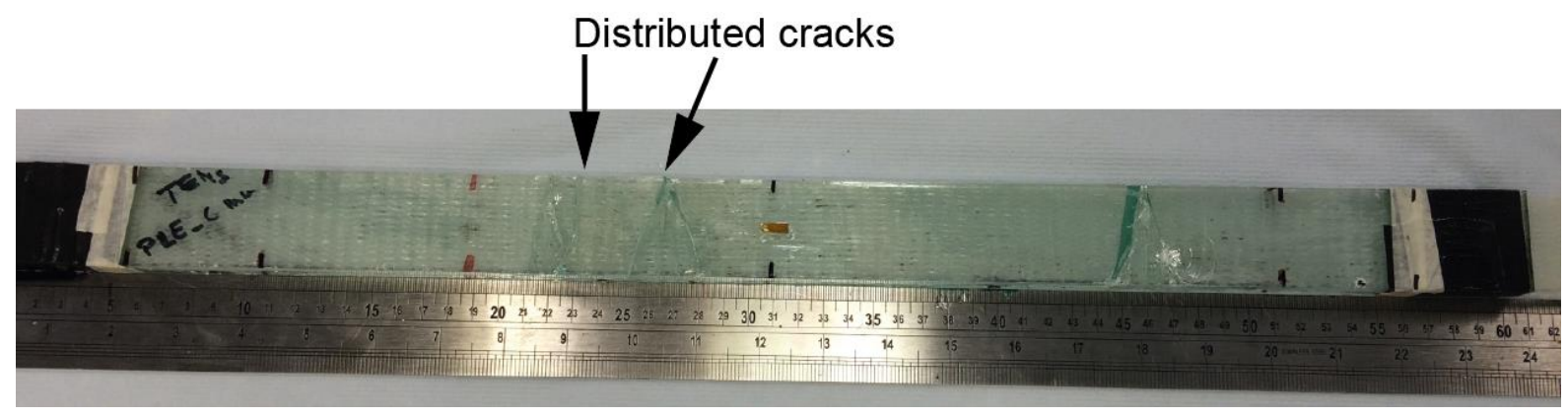

Fig. 11: Crack pattern in prestressed glass beams

\section{Structural Behaviour of Prestressed Glass Beams Compared to Reinforced and Unreinforced Glass Beams}

Fig. 12a compares the applied load vs. midspan deflection relationship of one of the prestressed glass beams against the two types of reference glass beams discussed in Section 8. The results show that the adhesively-bonded double layer beam (i.e. the beam without GFRP reinforcement) (shown in dashed lines in Fig 12) failed in a brittle manner at a peak load of $1520 \mathrm{~N}$. The prestressed glass beam and the GFRP reinforced glass beam showed linear behaviours until the formation of the first major crack. However, the peak load of the prestressed glass beam $(2160 \mathrm{~N})$ was $\sim 16 \%$ higher than that of the reinforced glass beam $(1870 \mathrm{~N})$. Fig. $12 \mathrm{~b}$ shows the measured surface stresses at midspan of the prestressed beam and the GFRP reinforced (i.e. unprestressed) beam within the pre-cracked regime. As expected, the results show the stresses increased linearly with the increase of the applied load. The results show that the maximum tension in all the beams were $\sim 38 \mathrm{MPa}$, but the peak compression of $\sim 54 \mathrm{MPa}$ in the prestressed glass beam was $\sim 7 \mathrm{MPa}$ higher than that of the reference beam. This confirms a potential contribution of $\sim 7 \mathrm{MPa}$ compressive prestress in the prestressed beams for increasing its load capacity compared to the reference GFRP reinforced beam. The increase in the peak load due to prestressing $(\sim 16 \%)$ is comparable with that of prestressed glass beams reported in the literature (e.g. [10], [11]). 
As the load-displacement relationships in Fig. 12a show, the prestressed glass beam displayed a notable post-cracked load carrying ability, similar to that of the reinforced glass beam. The flexural stiffness of the prestressed beam just after the peak load was higher compared to that of the GFRP reinforced beam; this may attributed to the relatively less cracking occurred in the prestressed beam owing to the compression caused by the GFRP. However, with the increase of the applied load the flexural stiffness of the prestressed beam approached that of the unprestressed beam (see Fig. 12a).

(a)

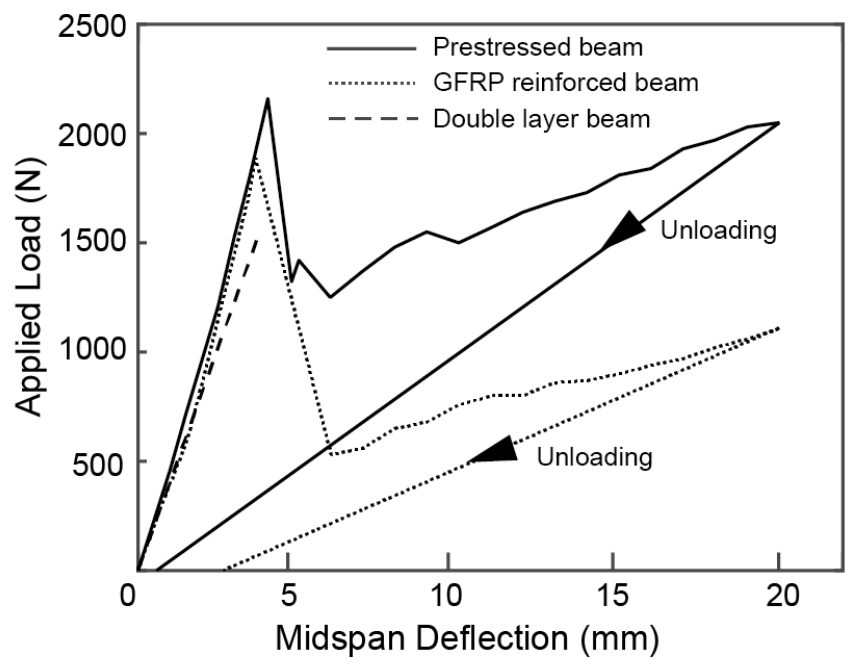

(b)

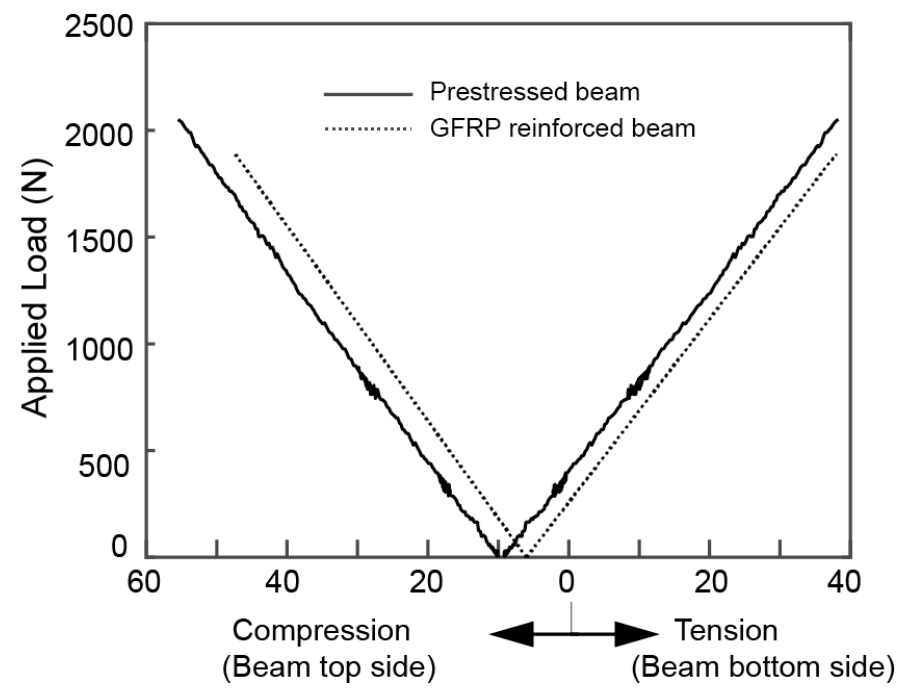

Surface stress (MPa)

Fig. 12: Comparisons between the prestressed and the reference glass beams: (a) Loadmidspan deflection relationships. (b) Measured surface stress data at midspan 
'Deflection ductility index', may be defined as the ratio of the additional midspan deflection after the peak load to that at the peak load. This suggests the ductility index of prestressed beam and the reinforced beam are over $400 \%$. These can be compared with the zero ductility index of the reference unreinforced double-layer beam. The notable ductility, similar to that of unprestressed reinforced beam, is indeed a key advantage associated with the prestressing technique proposed in the present study. In the prestressed beams, after the failure of the bottom glass sheet the shards of glass remained stuck to it (see Fig. 11), and hence glass did not fail in an explosive manner. A further beneficial structural characteristic of the present prestressed glass beams may be explored. The beams were unloaded at this maximum deflection of $20 \mathrm{~mm}$. The load-displacement relationships up on unloading of the beams shown in Fig. 12a, suggest the beams recovered the deflection upon unloading. This highlights the favourable post-cracked behaviour where potential ability of the beams to recover without a complete brittle failure after tensile failure of the bottom (i.e. tension) glass sheet.

\section{Conclusions}

The results of four-point bending experiments show that annealed glass beams prestressed using prestensioned GFRP showed an increased load capacity compared to equivalent glass beams reinforced with unprestressed GFRPs. However, since a small number of test specimens of dimensions smaller than actual building components was tested in the present study, a more generic validation of the results may be required. Furthermore, a comprehensive analytical/numerical investigation considering the effects of prestress, glass-GFRP bond and post-cracked behaviour will be required to determine optimal design details of the proposed prestressed glass beams. Similarly, a detailed investigation of potential shear coupling between the individual glass sheets may be required for a comprehensive characterisation of the load response and the failure behaviour of the proposed multi-layer prestressed glass beams. 
The prestressed glass beams showed a notable ductile post-cracked behaviour similar to the annealed glass beams reinforced with unprestressed GFRP strips. The results also show that the proposed glass prestressing techniques prevented premature GFRP bond failure or explosive final failure those commonly observed in the mechanically prestressed glass beams investigated in the literature.

The experimental results also showed that despite the heavy cracking, the pre-stressed beams recovered a significant part of the original deflection upon unloading.

The results confirm that the use of adhesively-bonded prestensioned GFRP strip enables the development of prestressed annealed glass beams which are stronger and ductile than conventional single and multilayer annealed glass beams.

\section{References}

[1] IStructE. Structural use of glass in buildings. 2nd ed.London: The Institution of Structural Engineers, 2014.

[2] Haldimann M, Luible A and Overend M. Structural use of glass. Zurich: International Association for Bridge and Structural Engineering, 2008.

[3] Louter C, Belis J, Veer F, Lebet JP. Structural response of SG-laminated reinforced glass beams; experimental investigations on the effect of glass type, reinforcement percentage and beam size. Eng Struct 2012; 36: 292-301.

[4] Blyberg L, Erik Serrano E, Bertil E, Sterley M. Adhesive joints for structural timber/glass applications: Experimental testing and evaluation methods. Int J Adhes Adhes 2012; 35:7687

[5] Louter C, Leung C, Kolstein H, Vambersky J. Structural glass beams with embedded glass fibre reinforcement. In: Proceedings of the Challenging Glass 2 - Conference on Architectural and Structural Applications of Glass. Delft, Netherlands, 2010.

[6] Speranzi E, Agnetti S. Flexural performance of hybrid beams made of glass and pultruded GFRP. Constr Build Mater 2015; 94: 249-262

[7] Achintha M, Balan B. Characterisation of the mechanical behaviour of annealed glassGFRP hybrid beams. Constr Build Mater 2017; 147: 174-184.

[8] Bedon C, Louter C. Numerical investigation on structural glass beams with GFRPembedded rods, including effects of pre-stress. Composite Structures 2018; 184: 650-661.

[9] Bedon C, Louter C. Structural glass beams with embedded GFRP, CFRP or steel reinforcement rods: Comparative experimental, analytical and numerical investigations. Journal of Building Engineering 2019; 22: 227-241. 
[10] Achintha M, Balan B. An experimentally validated contour method/ eigenstrains hybrid model to incorporate residual stresses in glass structural designs. J Strain Anal Eng Des 2015; 50: 614-627.

[11] Balan B, Achintha M. Assessment of stresses in float and tempered glass using eigenstrains. Exp Mech 2015; 55: 1301-1315.

[12] Bos FP, Veer FA, Hobbelman GJ, Louter PC. Stainless steel reinforced and posttensioned glass beams. In: Proceedings of the $12^{\text {th }}$ Int Conf on Experimental Mechanics, Politecnico di Bari, Bari, Italy, 2004.

[13] Louter C, van Heusden J, Veer F, Vambersky J, de Boer H, Versteegen J. Post-Tensioned Glass Beams. In: Gdoutos E.E. (eds) Fracture of Nano and Engineering Materials and Structures. Springer, Dordrecht, 2006.

[14] Louter C, Veer FA. (2007a). Large span reinforced glass beams, prototype research. IASS Shell Spat Struct. 2007: 1-10.

[15] Diaz M, Miguel J, Aguirregabiria B. Prestressed glass beams. Glass Performance Days. Tampere, Finland. 2011: 645-649.

[16] Louter PC. Reinforced and post-tensioned glass beams. Glass Performance Days, Tampere, Finland, 2013: 353-355.

[17] Jordao S., Pinho M, Martin JAP, Santiago A, Neves LC (2014). Behaviour of laminated glass beams reinforced with prestressed cables. Steel Constr 2014; 7(3): 204-207.

[18] Cupac J, Martens K, Nussbaumer A, Belis J, Louter C. (2017) Experimental investigation of multi-span post-tensioned glass beams. Glass Struct Eng (2017); 2 : 3-15.

[19] Burgoyne CJ, Chambers JJ. Prestressing with Parafil Tendons. Concrete 1985; 19: 1216.

[20] Martens K, Caspeele R, Belis J. Development of Reinforced and Posttensioned Glass Beams: Review of Experimental Research. J Struct Eng 2015; 142(5): 04015173

[21] Engelmann M, Weller B. Post-tensioned glass beams for a $9 \mathrm{~m}$ spannglass bridge. Struct Eng Int 2016; 26(2): 103-113.

[22] Louter C, Cupac J, Lebet JP. (2014) Exploratory experimental investigations on posttensioned structural glass beams. Journal of Facade Design and Engineering 2014; 2: 3-18.

[23] Cupac J, Louter C. Post-tensioned structural glass beams - comparative experimental study. In: Advanced Building Skins 2015: 165-172.

[24] Cupac J, Martens K, Nussbaumer A, Belis J, Louter C. Experimental investigation of multi-span post-tensioned glass beams. Glass Struct Eng 2017; 2(1): 3-15.

[25] Weller B, Engelmann M. An innovative concept for pre-stressed glass beams. In Proceedings of IABSE Conference, Nara, Japan 2015; 132-133.

[26] Bedon C, Louter C. Numerical analysis of glass-FRP post-tensioned beams - Review and assessment. Composite Structures 2017; 177:129-140.

[27] ASTM D3039/D3039M-95, Standard Test Method for Tensile Properties of Polymer Matrix Composite Materials, ASTM International, United States, 1995.

[28] Araldite2020 Product Sheet, Huntsman Advanced Materials, Basel, Switzerland, 2015.

[29] ASTM D638-02. Standard test method for tensile properties of plastics, ASTM International, United States, 2002.

[30] SCALP Instruction Manual, ver 5.0, GlassStress Ltd., Tallinn, Estonia (2015). 